DOI: $10.47456 / k r k r . v 2 i 4.33417$

\title{
Cinquenta anos de pedagogia da alternância no Brasil: conflitos e desafios
}

Fifty years of pedagogy of alternance in Brazil: conflicts and challenges

Paolo Nosella

Resumo: O presente trabalho busca relatar o processo histórico de origem da pedagogia da alternância no mundo e no Brasil, enfatizando como o movimento dos CEFFA's contribuem para a formação geral do ser humano. Inicialmente o texto realça o contexto político da Alternância no estado do Espírito Santo, no ano de 2016, a partir das investidas do Estado sobre este movimento, interferindo no seu funcionamento, justificado, também, pela não compreensão da articulação dos tempos e espaços de formação. É caracterizado uma escola em pedagogia da alternância, a partir dos princípios inspiradores dos CEFFA's e dos Instrumentos didático-pedagógicos, como possibilidades de resistência à invasão do Capital no campo. Ao final, como possibilidade de ampliar o processo de formação dos sujeitos envolvidos na Pedagogia da Alternância, além de preservar o germe desta proposta, propõe a criação de Centro Pedagógico Nacional.

Palavras-chave: Pedagogia da Alternância; educação do Campo; currículo; educação. Abstract: The present work seeks to report the historical process of origin of the alternation pedagogy in the world and in Brazil, emphasizing how the CEFFA's movement contributes to the general formation of the human being. Initially, the text highlights the political context of Alternation in the state of Espírito Santo, in 2016, based on the State's attacks on this movement, interfering in its functioning, also justified by the lack of understanding of the articulation of training times and spaces. A school in alternation pedagogy is characterized, based on the inspiring principles of CEFFA's and didactic-pedagogical Instruments, as possibilities of resistance to the invasion of Capital in the field. In the end, as a possibility to expand the training process of the subjects involved in Pedagogy of Alternation, in addition to preserving the germ of this proposal, he proposes the creation of a National Pedagogical Center.

Keywords: Alternation Pedagogy; rural education; curriculum; education.

\section{Escolas ameaçadas de fechamento}

Assim escreveu-me a Prof. Dra. Dulcineia Campos, Coordenadora do

Curso de Licenciatura em Educação do Campo da Universidade Federal do Espírito Santo (UFES):

Em fevereiro deste ano [2016], houve aqui um tenso debate entre as Escolas de Assentamento do MST e o Governo do Estado. Isso resultou também numa ocupação dos Pátios da SEDU pelo MST que durou 21 dias. O governo decidiu extinguir a Pedagogia da Alternância nessas escolas e, com isso, cancelou todos os contratos dos professores diminuindo as suas cargas horárias, ou seja, o horário reservado ao tempo comunidade não foi mais incorporado nos novos contratos. Além 
disso, essas escolas estão sob ameaça de fechamento. Esse problema chamou a atenção da sociedade, programas na rádio e envolvimento do Ministério Público e da própria UFES. Nesse sentido, o representante do Ministério Público convocou a UFES a dar uma resposta à sociedade sobre a metodologia em questão. Por isso, nesse evento, convidamos o Ministério Público, secretários municipais e estadual de educação, movimentos sociais, alunos da licenciatura, professores etc.

Assim, este seminário é uma resposta esclarecedora desta situação promovida pelo governo, considerada, por nós, desrespeitosa de uma história iniciada no Estado que é a Pedagogia da Alternância. ${ }^{1}$

Como é notório, a Universidade Federal do Espírito Santo (UFES), em 07 de março de 2016, se posicionou e repudiou tal atitude do Governo do Estado divulgando um Comunicado assinado pelos Docentes e Técnicos do Centro de Educação. Cito os trechos que se referem à Pedagogia da Alternância:

Educadores e Movimentos Sociais do Campo demandam da Secretaria de Estado da Educação (SEDU) o reconhecimento, a continuidade e a expansão da Pedagogia da Alternância; (...). A Secretaria de Estado da Educação do Espírito Santo desconsidera a Pedagogia da Alternância, uma vez que está excluindo as horas que são destinadas à realização do trabalho docente durante o tempo em que o aluno está em sua comunidade de origem. Essa Pedagogia é histórica entre os camponeses e vem sendo adotada pelas Escolas Famílias do Espírito Santo desde 1969 e pelas escolas de assentamento desde 1981. Ainda: pelos sistemas [oficiais] do ensino, pelas comunidades do campo, pelos movimentos sociais, sindicais e por estudiosos da educação. A metodologia da alternância articula aprendizagem escolar e aprendizagem no âmbito familiar/comunitário e é normatizada por meio do Parecer CNE $n^{\circ}$ 01/2006, dispondo que, durante as semanas em que os alunos ficam na propriedade ou no meio profissional, executem o Plano de Estudo, discutam sua realidade com a família, com os profissionais, provocando reflexões, planejando soluções e realizando experiências em seu contexto, irradiando, assim, uma concepção correta de desenvolvimento local sustentável.

Idênticas palavras estão impressas no folder organizativo do I Colóquio do Curso de Licenciatura em Educação do Campo. Com efeito, seu organizadores haviam percebido a necessidade de responder às muitas dúvidas e desafios existentes sobre a Pedagogia da Alternância.

\footnotetext{
1 E-mail de 3 de junho 2016.
} 
Em síntese: o conflito entre o Governo do Estado e as Escolas da Pedagogia da Alternância foi determinado pela confusa articulação entre os tempos na escola e os tempos na comunidade e, consequentemente, pelas imprecisas atividades profissionais dos professores durante os tempos na comunidade.

$\mathrm{Na}$ atual (perigosa) conjuntura política, os instrumentos didáticos próprios da Pedagogia da Alternância não podem se afastar do rigoroso cânone científico determinado pela tradição e pela ciência da educação. A incompreensão disso por parte dos agentes políticos pode desmerecer inovadoras experiências escolares e, no futuro, questionar até mesmo as escolas da alternância, historicamente bastante consolidadas. Portanto, de nossa parte, como militantes desse movimento pedagógico inovador, não podemos nos omitir no rigoroso estabelecimento do estatuto científico da Pedagogia da Alternância que, em algum caso, reconheçamos, é contaminado por interesses corporativos.

O movimento da Pedagogia da Alternância do Estado do Espírito Santo sofre hoje de crise de crescimento e consolidação. Aqui, como em outras partes do Brasil, busca-se sua identidade pedagógica e autonomia gerencial. Questões devem ser respondidas: é esse um movimento de escolas públicas ou privadas? De cultura geral ou profissionalizante? O método deve, preferencialmente, aplicar-se às escolas do Ensino Fundamental ou Médio? Deve, também, aplicar-se ao Ensino Superior? É um movimento exclusivo do campo ou também urbano? É multiculturalista ou interculturalista? É marcado ideológica e partidariamente ou é de formação humana politicamente "desinteressada"?

Cabe a todos nós, militantes dessa Pedagogia, responder a essas e outras questões que afligem o Movimento. Cabe a nós, portanto, definirmos com precisão a adequada dosagem e a correta articulação didática entre os tempos/escola e os tempos/comunidade, esclarecendo e assessorando as escolas na implementação dos instrumentos próprios da pedagogia da alternância. Por isso, necessita-se criar no Brasil um robusto Centro Pedagógico Nacional de Pesquisa e Formação da Pedagogia da Alternância, guardião e norma referencial dessa metodologia, que ofereça regularmente cursos de formação, promova eventos nacionais e internacionais para compartilhar 
criticamente pesquisas sobre a temática, editando, inclusive, uma excelente Revista própria.

Quanto à necessidade disso, ninguém tem dúvidas. Mas, quanto ao local e às modalidades concretas de seu funcionamento, existem perplexidades e divergências. Portanto, só a vontade política unitária, aliada à competência técnica e científica, capaz de superar ambições, interesses e diatribes individuais, fornecerá a resposta.

Este texto pretende colaborar na discussão dessa problemática, incentivando a criação e fortalecimento desse Centro Pedagógico Nacional.

\section{Origens do movimento}

As origens da Pedagogia da Alternância guardam o germe da autenticidade metodológica. Na cidade de Lauzun (França), em 1935, foi criada uma escola humanista, de qualidade, para os jovens trabalhadores do campo, evitando que se evadissem de seu território na forma de "êxodo forçado para a cidade". O sacerdote daquela cidade, Abbé Granereou (Le livre de Lauzun, 1968 $)^{2}$ constatava que, infelizmente, ser um bom aluno no campo significava uma coisa só: deixar o território natal e transferir-se para o grande centro. $\mathrm{Ou}$ seja, o campo fornecia para a cidade capital humano com elevados valores éticos, mas não formava seus próprios quadros de intelectuais orgânicos. Por isso, com as lideranças de sua paróquia, criou a escola da Pedagogia da Alternância. Como consequência importante dessa nova rede escolar, há hoje, na França, intenso intercâmbio, livre e criativo, entre os cidadãos que haviam optado para permanecer no campo e os que preferiam morar na cidade.

Semelhantes Escolas difundiram-se em vários estados da Europa, da África e da América Latina. No Brasil, o Movimento de Educação Promocional do Espírito Santo (MEPES) criou, no Espírito Santo, em 1968, as primeiras Escolas da Família Agrícola (EFAs) para os jovens trabalhadores do campo. A história é conhecida. ${ }^{3}$ Pioneiro fundador desse movimento foi o Padre Jesuíta

\footnotetext{
${ }^{2}$ Dessa obra foi feita a tradução para o português do Brasil, mas ainda não foi feita a edição nem divulgação.

3 Ver: NOSELLA, P. Origens da Pedagogia da Alternância no Brasil. $2^{\mathrm{a}}$ reimpressão, Edufes, Vitória, E.S., 2013.
} 
Humberto Pietrogrande. Não eram Escolas assistencialistas, nem profissionalizantes. Tampouco não pretendiam "fixar" o homem no campo. Visavam a impedir sua "expulsão", forçados a emigrar para as cidades por falta de condições mínimas de formação e desenvolvimento sócio econômico do território de origem. Em suma, o movimento promocional capixaba, inspirandose na experiência italiana e francesa, entendera que o interior do Estado precisava de uma escola que não reproduzisse de forma mecânica e empobrecida as escolas urbanas, mas priorizasse a integração moral e intelectual dos jovens com seu o ambiente originário, formando os quadros políticos e técnicos do desenvolvimento territorial. 4

O homem do campo percebera, há tempo, a existência de uma violenta contraposição entre seu território e o capital global. Eu mesmo presenciei, nos anos de 1968/69, às sondagens socioambientais realizadas no litoral de Guaraparí e Anchieta (E.S.) para aí construir o porto da multinacional da Marcona Corporation Belga (Samarco). Sem dúvidas, essa megaoperação econômica representava tremenda agressão ao meio ambiente e, sobretudo, às populações litorâneas. ${ }^{5}$ Em palestra proferida por um funcionário (sociólogo) da multinacional, ouvi, em 1968, em tom de estranha e cínica satisfação, que não encontrara resistência alguma por parte dos numerosos pequenos proprietários e/ou posseiros residentes no enorme território litoral a ser "adquirido" pela multinacional. Ao contrário, disse, todos se apressavam a vender sua propriedade para transferir-se na periferia de Vitória. Ao retornar ao mesmo local, 50 anos depois, constato que tudo mudou, infelizmente, para pior.

Grave agressão ambiental, naqueles mesmos anos de 1960 e 1970, ocorria, também, nos campos do norte do Espírito Santo. A empresa Aracruz Celulose atuava na produção de eucalipto expulsando os pequenos

\footnotetext{
${ }^{4}$ As escolas da Pedagogia da Alternância, dados do ano de 2012, funcionam em 21 Estados da Federação, totalizando 239 unidades e envolvendo 800 municípios. A perspectiva de expansão gradativa em todo o território nacional é de $10 \%$ ao ano sobre o total de recursos alocados. A Lei de Diretrizes e Bases da Educação Nacional (LDB) n 9.394/96, no artigo 23, cita a alternância como uma das formas de organização escolar. Com base nesse artigo, essa específica pedagogia foi reconhecida por unanimidade pelo Conselho Nacional de Educação em 15 de março de 2006 (Parecer CNE/CEB n 1/2006). (Nosella, 2013, p. 17).

5 Lembro, hoje, alguns trágicos efeitos, entre inúmeros outros, dessa megaoperação: 0 rompimento das barragens de Fundão e Bromadinho, da Vale/Samarco, que matou centenas de pessoas e cujo rastro de destruição chega ao litoral do Estado.
} 
proprietários, forçados a migrar às periferias das grandes cidades. Só permaneciam no território os funcionários, diretos e indiretos, da empresa. Mais tarde, após vários conflitos com indígenas e quilombolas, Aracruz Celulose entrara em crise e foi vendida para o grupo Votorantim, passando a se chamar Fibria.

Pela resistência do Movimento de Educação do Campo, a empresa Fibria mudou de tática, apresentando-se amigável, com "outra cara", isto é, relacionava-se simpaticamente com a comunidade, financiava projetos de piscicultura e outros, o que lhe gerou internacionalmente bom mercado. Obviamente, financiou também as campanhas de vários deputados. Eis o depoimento de um integrante do Movimento dos Pequenos Agricultores do E.S.:

A produção de eucalipto, em nosso estado, tem causado muitos danos ao meio ambiente como diminuição das águas. Em Nestor Gomes, São Mateus, onde tem a Escola da Família Agrícola (EFA) do $\mathrm{Km} \mathrm{41}$, a comunidade, cercada de eucalipto, está quase sem água. A diminuição das águas tem atingido vários municípios da região Norte/ES cobertos de eucalipto, como São Mateus, Conceição da Barra, pois chove pouco e uma árvore de eucalipto retira 20 litros de água/dia do solo. (RACEFFAES, 2012).

Hoje, a Aracruz Celulose, renomeada Fibria, como não pode mais comprar terras neste Estado, foi atuar em território da Bahia e do Maranhão e, para garantir matéria prima, trabalha com os agricultores em forma de fomento, procurando manter "boa" relação:

A nossa maior preocupação é que os agricultores se iludem e deixam de produzir alimentos, pois um hectare de terra, ocupado por 6 anos com eucalipto, na forma de fomento, rende 16.000,00 bruto. Descontando as despesas, sobra muito pouco para os agricultores. (RACEFFAES, 2012).

Entretanto, se a invasão do capital global é perversa, a estagnação arcaica também precisa ser superada. Por isso, o Movimento de Educação do Campo entendeu, no final da década de 1960, ser necessário criar uma nova escola que equilibre a modernidade científica com a solidariedade social, cultural e econômica. Isto é, uma escola cuja pedagogia adotasse como princípio fundamental a fidelidade às culturas do território sem rejeitar a modernização tecnológica. Ou seja, uma pedagogia que superasse, ao mesmo tempo, a 
tradicional escola técnico agrícola, que visava fixar o homem no campo e, também, a alienante escola de cultura geral urbana, abstrata, que só estimula o êxodo dos melhores alunos para os grandes centros.

Nesse contexto histórico e com esse objetivo educacional, foi lançado no Estado do Espírito Santo, a começar -como vimos- do ano de 1969, o movimento da Pedagogia da Alternância, cuja essencial fórmula didático-pedagógica era: cada turma de alunos do Ensino Fundamental II e Médio permanecia oito dias na Escola, em regime de internato, frequentando aulas em tempo integral, retornando, na sequência, por quinze dias, na família ou em outros espaços considerados formativos, onde aplicava o Plano de Estudo e desenvolvia atividades educativas cujo conteúdo se relacionava com sua realidade.

Obviamente, essa alternância não era mera justaposição ou mecânica sequência de espaços e tempos. O currículo integra escola e entorno social/produtivo, com estudos teórico críticos, despertando nas consciências dos alunos a necessidade de elaborar ousado projeto de desenvolvimento territorial, sustentável, integrador dos valores locais, nacionais e internacionais.

Em síntese, o objetivo da pedagogia da alternância, em seus níveis de escolarização fundamental e médio, é recriar nos alunos os valores fundamentais do humanismo, auxiliando-os na identificação de suas individuais inclinações intelectuais, morais e sociais, por meio de uma orgânica e refletida integração entre escola, família e território de origem. Os educadores dessas escolas sabem que os jovens que os procuram buscam, num nível imediato e superficial da consciência, garantir uma profissão rentável em curto prazo, mas, em profundidade, buscam mesmo o conhecimento elevado e clássico que lhes fora negado.

Por isso, pequenos agricultores familiares, comunidades indígenas, quilombolas e pomeranas, entre outras, buscam ainda hoje novos caminhos pedagógicos que preservem suas características culturais sem isolacionismo, mas também sem rejeição da modernidade técnico-científica. Ou seja, pretendem que, na escola, os jovens integram o enraizamento cultural à aprendizagem da ciência moderna universal, escopo da Pedagogia da Alternância. 


\section{Princípios inspiradores dos CEFFAS ${ }^{6}$}

A Pedagogia da Alternância inspira-se em alguns princípios fundamentais. A saber: em determinada concepção de homem, na teoria da aprendizagem baseada na alternância entre tempos de vida escolar e tempos de vida extraescolar, na interculturalidade entre os homens, na criação e expansão de escolas institucionalizadas e reconhecidas e, finalmente, numa base jurídica associativa autônoma. Vejamos:

\section{Natureza do homem}

O homem é essencialmente relacionamento radical, universal com sua terra. Ele se define essencialmente como habitante e filho da terra: é territorialidade. A íntima correlação entre território e cultura está registrada na linguagem. Assim comenta Saviani:

A própria etimologia da palavra latina "homo", da qual, pelo acusativo "hominem", derivou o vocábulo português homem, originariamente significa o nascido da terra, o terrestre, 0 habitante da terra. (SAVIANI, Prefácio, in NOSELLA, 2013).

Ou seja, território não é um espaço abstrato do planeta, é uma relação cultural que denota concepção de vida e de valores; expressa identificação econômica, social e cultural do ser humano, conforme definição tão cara a Milton Santos: "A territorialidade humana pressupõe também a preocupação com o destino, construção do futuro, o que, entre os seres vivos, é privilégio do homem." (SANTOS, 2011, p. 19).

O território confere concretude à própria história humana. Ao contrário, o instrumento técnico, informacional e financeiro, confere-lhe a dimensão abstrata globalizante. Em outras palavras: com meios técnicos e com dinheiro o homem conquista, invade, domina os territórios, estabelecendo neles, em dimensões globais, o conflito entre culturas, inclusive, no interior de uma mesma. Com efeito, "a divisão territorial do trabalho cria uma nova hierarquia entre lugares,

\footnotetext{
${ }^{6}$ O termo CEFFAs, Centros Familiares de Formação por Alternância, foi estabelecido nacional e internacionalmente para uniformizar a linguagem entre as Escolas no mundo que praticam essa metodologia.
} 
redefinindo, a cada momento, a capacidade de agir das pessoas, das firmas e das instituições" (SANTOS, 2011, p. 21).

O campo gerou a cidade, não o inverso. A cidade, filha do campo, pela força do instrumento técnico, pode destruir sua matriz e, com isso, destruir a si mesma. Mas, no caminho inverso, o homem pode, também, estabelecer entre campo e cidade um relacionamento orgânico, equilibrado e dialético. Na construção desse caminho, os habitantes da cidade e do campo tentam se unir politica e economicamente, começando pela criação de uma escola humanista, moderna, unitária que priorize justamente o enraizamento territorial. Assim, o campo se urbaniza e a cidade se humaniza.

O campo não existe sem o homem-do-campo. O latifúndio e a monocultura não são "campo". Os chamados "desertos verdes" de cana de açúcar, de soja, pastos etc. não são propriamente campos. São, na superfície, o equivalentes aos lençóis de petróleo debaixo da crosta terrestre.

Concluindo, a primeira característica da Pedagogia da Alternância consiste no "ancoradouro" num território concreto, individualizado, pela "criação de suas instituições escolares que emana de uma iniciativa local, visando a atender a uma necessidade de formação encampada pelas famílias aí residentes e não de uma decisão político-administrativa abstrata." (GIMONET, 2014, p. 18).

\section{Integração de formação escolar e extraescolar}

Quem educa o ser humano, afirmam os clássicos pensadores da educação, é o "todo educante", a totalidade. Na linguagem da antiguidade grega é o "pantak-ou", isto é, de toda parte, onde quer que esteja, seja onde for. Portanto, o educador é todo o território (família, estado, instrumentos materiais, meios de comunicação, instituições formadoras etc.):

Aqui temos um ensinamento de Platão que eu gosto sempre de repetir. Depois de ter falado de ginástica e música como eixos da educação antiga (a ser conservada, corrigindo-a) diz, porém, que aquilo que educa é o que na sociedade existe em todo lugar, o pantak-ou. (MANACORDA. 2007, p. 16).

Em outras palavras, todo processo educativo necessariamente funciona integrando tempos formalmente educativos com tempos informalmente educativos, alternância de situações de vida familiar, social e profissional com 
programas escolares, na dosagem adequada, conforme ensina a ciência da educação.

\section{Interculturalismo e multiculturalismo}

O fenômeno de interculturalismo não é específico da atualidade. É primordial na história da humanidade. Hoje, com efeito, utiliza-se mais frequentemente a expressão multiculturalismo que conota algo diferente. Os dois termos são equivalentes? São sinônimos? Qual dos dois é mais apropriado à filosofia da educação da Pedagogia da Alternância? O prefixo inter refere-se a intercâmbio, integração, síntese, ecletismo, unificação cultural; multi refere-se a várias culturas justapostas ou até contrapostas, às vezes refratárias a um unitário processo de integração e de hegemonia político-cultural, permanecendo, portanto, em tensão entre si. Nesse sentido, enquanto o interculturalismo já conota solução de conflito, o multiculturalismo expressa contraposição entre culturas diferentes e, portanto, exige do poder do Estado políticas públicas apropriadas a esses conflitos.

O debate atual sobre interculturalismo ou multiculturalismo não é homogêneo, conhecem numerosas variantes. Uma delas é a complexa e ardorosa movimentação política existente hoje no Brasil que, sobretudo a partir da década de setenta, determinou o "Movimento de Educação do Campo" que, de um lado, reivindica e articula específicas políticas públicas multiculturais, cujo ideário é o desenvolvimento sustentável por meio de uma educação voltada para os valores da territorialidade, mas, de outro lado, promove e articula atitudes e fatos que demarcam territórios contrapostos. O movimento da Pedagogia da Alternância prefere levantar a bandeira do interculturalismo, pois afirma "ser possível e necessário construir um sistema de valores no qual todas as culturas possam se encontrar" (TARIM, 2010, p. 63-66). O Movimento da Pedagogia da Alternância, arrolando um conjunto de autores e obras, defende a proposta do "universalismo crítico" e da ética intercultural de democracia, justiça, direitos no mundo contemporâneo, apontando precisos limites do cosmopolitismo extremado.

\section{Movimentos sociais e instituições escolares}


Os movimentos sociais são a arqueologia das instituições. Surgem espontaneamente, reivindicando políticas e iniciativas que a sociedade civil necessita e que, ainda, não existem. Os Movimentos Sociais surgem com ímpeto. Sua organização apresenta-se tosca, parecendo rude, espontânea. Historicamente, se apresentam defendendo necessidades importantes e orgânicas à sociedade civil. Em geral, suas reivindicações, quando consideradas oportunas, são atendidas pelos poderes políticos e acabam por se "instituírem" como públicas estruturas permanentes e regulamentadas. Foi dessa forma que também o Movimento Social da Pedagogia da Alternância surgiu nos anos de 1930 na França e nos anos de 1968 no Brasil. Não existiam, até então Escolas da Alternância legalmente reconhecidas e regulamentadas, até que sua necessidade educativa, sobretudo, para o homem do campo, foi reconhecida. Hoje, a Pedagogia da Alternância é um projeto sócio educativo ambicioso; ultrapassou o momento histórico puramente reivindicativo característico dos Movimentos Sociais; conserva a força associativa de base, exibe no seu DNA as mesmas características dos Movimentos Sociais, mas não mais se identifica com eles.

Compreendem-se, portanto, certas ambiguidades e diferenças entre Movimentos Sociais e Escolas da Pedagogia da Alternância, todavia, há solidariedade e colaboração recíprocas, uma vez que as raízes históricas são socialmente da mesma natureza, isto é, populares.

\section{Base jurídica e autonomia administrativa e pedagógica}

O movimento da Pedagogia da Alternância nasceu e se desenvolveu no âmbito de movimentos sociais de natureza associativa ou cooperativa. Sustentase na mobilização e organização popular, sendo as famílias dos alunos corresponsáveis das escolas. Por opção histórica e filosófica optou por ser uma escola pública, de gestão comunitária, mas não estatal. Guardou sempre distância da vinculação direta (burocrática e administrativa) dos Governos (Federal-Estadual e Municipal) e das Instituições Religiosas (Igrejas). Todavia, por ser um movimento educativo essencialmente popular, necessita, por direito democrático, do apoio dos Governos e das Igrejas. Aliás, nesse sentido, as 
Escolas da Pedagogia da Alternância fazem jus às afirmações marxianas, conforme atesta Mario Alighiero Manacorda:

Eu retorno a Marx porque ele disse as coisas de forma tal que é sempre possível nelas reconhecer um germe do futuro. Sobre educação, ele falou de instrução intelectual, física e tecnológica para todos, e acrescentava outra coisa que é a base da assim chamada economia política em perfeita coincidência com a idealidade da grande tradição liberal, isto é, que é preciso distinguir o Governo do Estado: escola estatal não significa escola submetida ao governo. Precisa excluir Estado [governos] e Igreja de qualquer interferência na escola, não ensinar matérias que permitam interpretações de partido e de classe. Assim, (em Marx) existe este dúplice ensinamento: a) uma escola para todos que seja intelectual, física e tecnológica (tecnológica, teórica e prática, não a escola pluriprofissional predileta pelos burgueses) e b) a liberdade da escola de qualquer interferência do poder político. Esses dois temas, ainda hoje, valem para todos. MANACORDA, DVD, 2007, p. 13).

Obviamente, essa proposta pressupõe por parte de Estado a adoção de políticas públicas com vistas a garantir autonomia de gestão das unidades escolares e recursos regulares por parte dos governos (local, estadual e federal).

\section{Instrumentos didático-pedagógicos}

\section{Alternância de tempos e espaços de formação}

Sem dúvida, o instrumento didático mais importante e original dessa pedagogia é sua especial Alternância entre tempo-escola e tempo extraescolar. Já foi dito. Mais que "instrumento didático-pedagógico". Essa é a estrutura estruturante princeps das escolas da alternância.

A rigor, toda instrução escolar utiliza-se de alguma alternância. Mesmo as escolas urbanas funcionam numa determinada alternância, pois, num período do dia os alunos permanecem na escola e, noutro, na família ou em diferente espaço formativo. Neste caso, trata-se de alternância em sentido genérico, lato sensu.

Diferentemente, a Alternância stricto sensu aplicada nos Centros Familiares de Formação por Alternância (CEFFAs) consiste numa peculiar dosagem e integração didática entre os tempos de escola e os tempos fora dela. 
É uma alternância, sobretudo (mas não exclusivamente), à situação dos alunos moradores do campo, fisicamente distantes da instituição escolar.

A duração desses dois tempos pode variar conforme situações concretas. A experiência brasileira sugeriu que a alternância escola-comunidade mais adequada é de uma ou duas semanas na escola e duas semanas na família ou em outras instituições formativas. Assim, os alunos chegam à escola no domingo e retornam à comunidade no sábado depois do almoço.

Enfim, de forma geral, toda aprendizagem se processa por meio de alguma alternância, mas só o acumulo científico ocorrido no movimento da Pedagogia da Alternância pôde fornecer os procedimentos didáticos e científicos pertinentes. Em outras palavras: se é verdade que em todo e qualquer processo de ensino-aprendizagem sempre há algum tipo de alternância, somente uma específica e lógica organização didática, com currículo orgânico e unitário, consegue otimização a integração formativa do tempo escola com o tempo fora da escola. Neste caso, trata-se da alternância pedagógica stricto sensu.

\section{Mobilização e organização das lideranças locais}

O Movimento da Pedagogia da Alternância considera essencial realizar, antes da criação de uma escola, reuniões com as lideranças culturais, políticas, religiosas, populares em geral, para apresentar a proposta dessa Pedagogia e solicitar-Ihes apoio concreto e contínuo. Essencial é criar Associações com essa finalidade.

\section{Mais que "professores"}

A Pedagogia da Alternância exige educadores de um novo tipo. Não meros professores, não transmissores frios de conteúdos pré-estabelecidos, nem docentes disciplinares. Exige educadores animadores, acompanhadores, especialistas dessa pedagogia trabalhando em equipe, uma vez que os alunos dessas escolas constroem sua formação e seu devir profissional de forma diferenciada. ${ }^{7}$ Exige, enfim, parceria educativa entre todos os atores do sistema:

\footnotetext{
7 Observe-se que nos CEFFAs do Brasil, os professores são chamados "monitores", conotação inadequada na linguagem da comum ciência pedagógica. Termos como "mestres", "educadores", "preceptores" parecem mais apropriados. Hoje, no Movimento, esta questão ainda permanece sub judice.
} 
pais, mestres de estágio, monitores e outros intervenientes, porque toda educação representa uma obra coletiva. (GIMONET, idem, ibidem).

\section{Participação das famílias}

É fundamental dessa concepção pedagógica a cooperação, a partilha do poder educativo. As famílias representam, sobretudo, a autoridade moral; os professores, especificamente, a autoridade técnica intelectual. São duas faces do mesmo processo formativo. Para tanto, podem ser realizadas variadas e fecundas atividades: semanas de formação em que participam famílias, alunos e mestres; visitas às famílias; produção e distribuição de boletins informativos etc.

\section{Currículo estruturado por temas geradores}

A cada sessão escolar, um tema específico deve ser destacado, começando pelos mais próximos aos alunos, como a constelação familiar, a casa, a propriedade, a comunidade ou capela, o município, o estado, a nação, o mundo e, finalmente, o cosmo. Sempre em perspectiva histórica crítica.

\section{Plano de estudo e caderno da realidade}

O Plano de Estudo é constituído por perguntas ou questões elaboradas no final de cada sessão escolar. Um questionário, em suma. Todo aluno deverá aplicá-lo em sua família, ou comunidade, ou instituição cultural, científica, técnica nos dias extraescolares e trazê-lo para a Escola na sessão seguinte. As respostas, colocadas e analisadas em comum em sala de aula, redefinidas e revisadas, formarão o Caderno da Realidade de cada aluno, primeiro 'livro' a ser construído, ao lado dos demais livros científicos, técnicos, culturais e artístico.

\section{Vida em comum residencial ou internato}

Trata-se do tão questionado "internato". Com efeito, a lembrança dessa forma de vida dos antigos colégios de internato, seminários, colégios militares, 
instituições para filhos indesejados, rejeitados, órfãos, geralmente não é boa. Entretanto, é preciso entender que não se trata aqui de longas e ininterruptas permanências num internato longe da família e comunidade de origem. São poucos dias por sessão, cerca de 8 a 10 dias por mês. Seu efeito negativo está, portanto, definitivamente descartado. Ao contrário, os efeitos positivos de formação são ricos: hábitos disciplinares de estudo e de organização da casa, solidariedade criada na arrumação e manutenção da escola, nas brincadeiras, nos serões culturais de noite, nas apresentações de peças de teatro durante os serões, no acesso amplo e livre à biblioteca etc. Tudo isso permite afirmar a positividade desse regime de internato em alternância, ressalvadas, obviamente, situações particulares de alunos que moram próximos à escolas e que desejem voltar à família para pernoitar.

\section{Viagens e visitas de estudo}

As viagens e as visitas de estudo não são atividades periféricas, momentos de distração. São instrumentos didáticos essenciais ao currículo da Escola da Pedagogia da Alternância. Uma boa viagem de estudo, frequentemente, pode ser tão ou mais formativa do que uma disciplina curricular regular. Obviamente, preparada com critério e rigor em três momentos: a) planejamento (definição dos objetivos, organização, levantamento das questões a serem apresentadas às pessoas durante a viagem etc.); b) execução com acompanhamento de docente; c) colocação em comum para análise crítica e registro no Caderno da realidade.

Sergio Zamberlan conclui que a Viagem de Estudo é um momento de formação geral e profissional; dinamiza e enriquece o currículo; aproxima o meio sócio produtivo à escola; valoriza a cultura popular; enriquece o capital social (relações sociais e profissionais); favorece o intercâmbio entre realidades diferentes. (ZAMBERLAN, 1996).

\section{Estágios profissionais condizentes à personalidade do jovem}

Desnecessário destacar a importância formativa desses estágios. Entretanto, vale a pena observar que não é fácil identificar o estágio formativo 
adequado para cada jovem, uma vez que o pré-adolescente e o adolescente passam por uma fase psicológica complexa e indefinida. Não conseguem identificar com clareza sua tendência profunda e fundamental. Frequentemente, as escolas organizam estágios pensando somente no mercado ou no currículo do curso. Nem sempre isso dá resultados positivos. Conversando com alunos de um curso para técnico agrícola, por exemplo, alguns falaram que seu desejo era estagiar em escritórios de contabilidade, outros em firmas de divulgação e outros ainda em laboratórios de fotografia etc. Por isso, é essencial conversar tranquila e francamente com os alunos e, talvez, precise organizar grupos menores para diferentes estágios profissionais.

\section{Avaliação constante e integrada}

Aplicar com rigor esses instrumentos de formação não é tarefa fácil. Constante e integrada avalição torna-se indispensável. Os alunos precisam avaliar o própria formação durante o percurso; da mesma forma, os educadores, a Associação de pais e mestres e até mesmo as lideranças locais. A escola como um todo fará sua avaliação em Assembleia ou Congresso geral; os setores dela, sem burocratismos nem autoritarismos, farão sua própria avaliação.

Tarefa difícil, sabemos, mas rica de resultados.

\section{Conclusão: a crise como oportunidade}

Diante da atual crise, que todos desejamos, quanto antes, superar, é preciso investir no campo e resgatar a dívida social contraída com os pequenos e médios agricultores, por meio de elevada formação dos jovens. (D. Luciano Mendes, 1992). Nessa perspectiva, os Centros da Pedagogia da Alternância (CEFFAs), após 50 anos de existência, são chamados a considerarem a crise como momento de oportunidade.

Uma iniciativa necessária para evitar que essa Pedagogia seja descaracterizada e, portanto, hostilizada e até destruída por forças políticas insensíveis a certos valores, é criar um Centro Pedagógico Nacional de Pesquisas e Formação em Pedagogia da Alternância, de elevado nível científico. 
A atual crise evidenciada nos embates com representantes do governo pode ser a oportunidade histórica para a Pedagogia da Alternância voltar-se às origens e resgatar stricto sensu a autenticidade do modelo, garantindo a máxima qualidade científica dos seus alunos que, intelectual e moralmente, deverão ser os melhores. Com efeito, ao lado do comprometimento com o próprio território, os alunos dos CEFFAs saberão enfrentar e vencer em qualquer vestibular do País. Isso é possível se as Associações das Escolas da Pedagogia da Alternância, os Movimentos Sociais, as Instituições de Ensino Superior e outras instituições laicas e religiosas se unirem na criação de um forte Centro Pedagógico Nacional de Pesquisa e Formação da Pedagogia da Alternância.

\section{Referências}

FICHTNER, Bernd; FOERSTE, Erineu; LIMA, Marcelo; SCHÜTZ-FOERSTE, Gerda Margit (Orgs.) . Cultura, dialética e hegemonia: pesquisa em educação. 2. Ed. Vitória : Edufes, 2013.

GIMONET, Jean-Claude. Praticar e Compreender a Pedagogia da Alternância dos CEFAs. Tradução de Thierry de Bughrave. Petrópolis: Vozes, Paris: AIMFR - Associação Internacional dos Movimentos Familiares de Formação Rural, Coleção AIDEFA, 2007.

GIMONET, Jean-Claude. Da experiência pedagógica à alternativa educativa. In : Carlos Bauer et. Al. (Orgs.). Jundiaí, Paco Editorial: 2014.

GRANEREAU, Abbé. Le Livre de Lauzun . 9a ed. Paris: Comité d'Action, 1968. (Atualmente, no Brasil, existe a tradução e edição da mesma obra, in E-Book, gratuito, com o título $O$ livro de Lauzun - onde começou a pedagogia da alternância. Edições UFC, Fortaleza, 2020). ${ }^{8}$

LUCIANO, D. Mendes de Almeida. Jornal Folha de S. Paulo, 11 de janeiro, de 1992.

MANACORDA, Mario Alighiero. Aos educadores brasileiros. DVD. HISTEDBR, Unicamp, Campinas, SP. 2007.

NOSELLA, Paolo. Origens da Pedagogia da Alternância no Brasil. Vitória: Edufes, 2013, $2^{\mathrm{a}}$ reimpressão.

RACEFFAES, boletim informativo, Vitória, E.S., 2012.

\footnotetext{
${ }^{8}$ Atualmente, no Brasil, existe a tradução e edição da mesma obra, in E-Book, gratuito, com o título $O$ livro de Lauzun - onde começou a pedagogia da alternância. Edições UFC, Fortaleza, 2020.
} 
SANTOS, Milton. Por uma outra globalização. Rio de Janeiro: Record: 2011.

TARIM, Stefania. Etica e política nell' época dell'interculturalità. In: Critica marxista. Roma, $n^{\circ}$ 5, 2010.

ZAMBERLAN, Sergio. Viagem e Visita de Estudo. Centro de Formação MEPES. Piuma, E.S., 1996.

Sobre os autores

\section{Paolo Nosella}

nosellap@terra.com.br

Pesquisador Sênior do CNPq. e Professor do PPGE da Universidade Federal de São Carlos, SP (UFSCar). 